\title{
Understanding the complex family experiences of
}

\section{Behavioural Family Therapy}

P

Abstract

Family psychoeducational interventions including Behavioural Family Therapy have an impressive evidence base in the treatment of schizophrenia. While there are challenges in their implementation including the engagement of families, in the few qualitative studies of Behavioural Family Therapy, families report largely positive experiences. Understanding more about families' experiences of Behavioural Family Therapy could guide changes to practice to improve implementation. This qualitative study involved interviews with 20 clients diagnosed with schizophrenia and 20 relatives who participated in Behavioural Family Therapy in Australia. Participants valued sharing experiences between family members and their relationship with the practitioner. Unlike previous studies they reported discomfort in sessions and disappointment in aspects of Behavioural Family Therapy. Greater emphasis on addressing this discomfort and on therapeutic alliance may help overcome implementation challenges.

\section{Practitioner Points}

This is the author manuscript accepted for publication and has undergone full peer review but has not been through the copyediting, typesetting, pagination and proofreading process, which may lead to differences between this version and the Version record. Please cite this article as doi:10.1111/ 1467-6427.12139. 
- Practitioners can use their therapeutic alliance with families to promote shared understanding by providing information as well as facilitating information-sharing between family members.

- Practitioners need to recognise and respond to the high levels discomfort experienced by families and particularly the vulnerability of the person with schizophrenia.

- An increased focus on engagement and the therapeutic alliance may improve the implementation of BFT in services.

\section{Introduction}

Behavioural Family Therapy (BFT) is a form of family psychoeducation, a group of approaches that focus on providing information about mental illness and skills training to help families support the recovery of their mentally ill relative and reduce stress within the family. Family psychoeducation has been the subject of extensive international research indicating that it improves outcomes for people experiencing schizophrenia and their families (McFarlane, 2016; Pharoah, Mari, Rathbone, \& Wong, 2010). However only a small number of British studies have sought to understand the actual experience of families who have participated in BFT and similar forms of family psychoeducation (Budd \& Hughes, 1997; Campbell, 2004; James, Cushway, \& Fadden, 2006). This qualitative study explores the experience of family participants in BFT in Australia.

BFT consists of components of; individual goal setting, information sharing about mental illness and skills training in communication and problem solving in the 
context of a supportive relationship between a practitioner and a family where a member experiences mental illness (Mueser \& Glynn, 1999). In a number of controlled trials BFT has been associated with a reduction in relapse for people experiencing schizophrenia (Berglund, Vahlne, \& Edman, 2003; Glynn et al., 1992; Randolph et al., 1994; Schooler et al., 1997). BFT has also been found to reduce symptoms and the use of psychotropic medication and improve the functioning of the person with the condition (Berglund et al., 2003; Magliano et al., 2005; Magliano, Fiorillo, Malangone, De Rosa, \& Maj, 2006b; Montero et al., 2001; Schooler et al., 1997). In relation to family members, BFT has been associated with reduced carer burden, improved carer coping and family functioning (Berglund et al., 2003; Magliano et al., 2005; Magliano et al., 2006b; Mueser et al., 2001).

While outcome research is vital in demonstrating the value of $\mathrm{BFT}$, it provides less guidance about the practice of BFT and how the model might be improved (Mairs \& Bradshaw, 2005). Furthermore, despite impressive benefits, BFT and other forms of family psychoeducation are not provided in many jurisdictions (Fadden, 2006; Haddock et al., 2014; Rummel-Kluge, Pitschel-Walz, Bauml, \& Kissling, 2006). Implementation of BFT in mental health services has proven challenging with low levels of uptake by practitioners following training (Fadden, 2006; Onwumere, Grice, \& Kuipers, 2016). Another challenge to increasing participation in BFT concerns difficulties in engaging and retaining families in BFT (Fadden, 2006; Harvey \& O'Hanlon, 2013; Magliano et al., 2005; Magliano, Fiorillo, Malangone, De Rosa, \& Maj, 2006a; Onwumere et al., 2016). 
Although a diverse range of factors influence the extent of implementation of new practices, one useful avenue for addressing these difficulties is to consider adaptations to intervention models and their associated training programs. Such adaptations could be informed by a deeper understanding of families' and clients' experience of participating in BFT with the potential to improve engagement of families, enhance the relationship between the family and mental health practitioners and reduce premature cessation of the intervention (Lambert, Skinner, \& Friedlander, 2012; Priebe \& McCabe, 2006)

However, despite the potential value of understanding the family and client perspectives concerning participating in $\mathrm{BFT}$, their experience has been infrequently investigated. Previous research concerning family experience of BFT or similar interventions is limited to three studies conducted in the United Kingdom with largely English-speaking families (Budd \& Hughes, 1997; Campbell, 2004; James et al., 2006). The common themes that emerged in these studies relate to the importance of practitioners' personal qualities and the value of collaborative and supportive relationships between family and practitioners (which BFT enhanced). These accounts of the experience of BFT were almost exclusively positive with families endorsing the value of the approach (Budd \& Hughes, 1997; James et al., 2006). Building Family Skills Together was a project based in Melbourne, Australia, that aimed to establish BFT in an adult community mental health service and research both the process of implementation (O'Hanlon, 2015) and the outcomes(Hayes, 2014). The research questions in this study were: What are the client and family experiences of BFT in an Australian mental health context? How do 
these experiences provide guidance about how the BFT model could be best practiced and implemented in mental health services?

\section{Method}

\section{Setting}

Behavioural Family Therapy (BFT) was conducted at two community mental health centres located in disadvantaged urban and suburban areas of Melbourne, Australia. All of the practitioners at each of the centres completed a five day training program and were provided with a practice manual developed by the Meriden Family Programme (Falloon et al., 2004). Practitioners were also provided with follow up support in use of the model, including co-working as part of the Building Family Skills Together project.

\section{Intervention}

Families were usually seen for BFT sessions at weekly or fortnightly intervals for one hour at a home or office setting. The length of contact varied with an average of 12 sessions $( \pm 8 \mathrm{SD})$ conducted over six to nine months. Most sessions were conducted with two practitioners, one of whom was directly responsible for the client's ongoing treatment and usually a novice practitioner of BFT. The other was an experienced family therapist and BFT practitioner from a specialist family mental health service that was supporting the implementation of the approach.

\section{Participants}

Forty-seven families who had participated in BFT were approached to participate in interviews about their experience of the intervention. Nineteen clients and 17 carers (ten parents, three spouses and four siblings) completed individual 
interviews; four family dyads ( 2 parent/adult child, 1 husband/wife, and 1 sibling pair) completed the conjoint interviews. Three clients and one relative participated in both the individual and conjoint interviews. Overall 20 clients and 20 carers were interviewed.

The age of the clients ranged from 18 to 60 years. Fourteen were male and seventeen were never married. Seven were working at least part-time.

The relatives' age ranged from 25 to 61 years. Thirteen were female, eleven were currently partnered, and ten were working at least part-time.

Fourteen of the clients lived with their relatives, and 16 of the relatives lived with their family member who was a client. Three clients and six family members were born overseas (three clients and five carers from Europe and one carer from Asia).

\section{Data Collection}

Two interview approaches were used. The first was in-depth hour-long interviews with the client and self-nominated family member interviewed together by the first author $(\mathrm{BOH})$, six to twelve months after the conclusion of BFT sessions. Using combination purposeful sampling (Patton, 2002), clients and their families were identified firstly, on the basis that they had participated in at least eight sessions of BFT. Secondly, families were selected to reflect the mix of cultural backgrounds and family constellations (partner, parental and sibling groupings) of the treatment group.

The second approach involved brief (10-15 minutes) semi-structured interviews, using an interview guide, and with a self-nominated family member and 
the client separately. The second author conducted these interviews immediately following the conclusion of BFT sessions.

The two different interview approaches maximised the opportunity to capture the widest variation in responses, due to differences in time after treatment (both immediate response and later reflections), analogous to post-testing and follow-up assessments in quantitative methods), interview length, interview structure and sampling strategy. The use of conjoint and split interviews allowed exploration of a wider range of responses to the family sessions. Shared experiences were discussed in conjoint interviews and split interviews allowed participants to freely state reflections on their experience that they might have been uncomfortable expressing in front of other family members.

Interviews were recorded digitally and then transcribed or through field notes taken by the interviewer.

\section{Data analysis}

The data was thematically analysed (Saldaña, 2009). In-depth interviews underwent an independent editing process to eliminate repetitions and redundancies. Material was descriptively coded, a methodology well suited to the analysis of different data formats (Saldaña, 2009). This involved using a word or phrase to summarise the basic topic of a segment of qualitative data. The coded data were then subjected to further categorisation and reflective analysis by the first two authors to generate a series of themes. A third refinement was undertaken by these authors independently to demonstrate reliability in the thematic coding process where data from the first coding was independently categorised to the 
secondary themes. There was a very high concordance in classification and any differences in classification were discussed until consensus was obtained.

\section{Ethical considerations}

The research procedures and protocol were designed and carried out in a manner consistent with the Helsinki Declaration. Ethics approval for the conduct of interviews was obtained from the relevant hospital and university ethics committees. Consent for the in-depth interviews conducted by the first author $(\mathrm{BOH})$ was obtained by a research assistant. This was done to reduce the likelihood that families would feel obliged to participate in interviews as a consequence of their relationship with the interviewer who had also been one of the experienced family therapists who had conducted BFT with the family. For the briefer interviews case managers approached eligible participants to obtain permission for a researcher to contact them. For both groups interviewed, consent was required from the client before family members were approached. Names of participants were changed to preserve anonymity.

\section{Findings}

The four major themes and the sub themes that emerged are described below. The interview contexts are identified as Family Interview (FI) and Brief Interview (BI).

\section{Engagement and Early Sessions}

Reflecting on their experiences of engagement, family members described their expectations about how BFT might help and their apprehensions about participation. 
Hopes and expectations. Family members' hopes for how BFT might assist their family varied. Frequently family members linked their expectations to specific components of the BFT model, most often information sharing and communication skills.

I know for me I just wanted more information about what was going on. (Paula, sister, (FI))

Yeah, I was hoping it would help with the family understanding and also knowing what to do as well. (Conor, client, FI)

There was always a lot of sort of blame being shunted around... I thought...[BFT] was actually a good way of maybe rebuilding better communication. (Arthur, father, Fl)

Apprehensions about BFT. Although family members generally had positive expectations that BFT could assist the family, this was balanced by a range of concerns about what might happen. Uncertainty about how others might respond in sessions and the potential for conflict were often reported.

Very nervous...I was a bit stressed and I was a bit anxious...I don't know how the family are going to take it either...It was going to be tough, because I always find it [the illness] tough to talk about. (Conor, client, FI)

Oh there's definitely some nervousness about it because...you don't know what you're going to fire at us, and...you have to bare your soul a little bit, and that's not comfortable... I mean the session like that potentially could end up in a real bun fight. (Arthur, father, FI) 
I was quite ambivalent about doing it because I thought it might stir up a hornet's nest, and rock the boat... And I felt that I might be blamed for all the problems too (Irene, mother, $(B I))$

\section{Participation in BFT}

When families participated in sessions they described aspects of the sessions that they found uncomfortable as well as enjoyable or rewarding.

The client being in the "hot seat." Clients reported high levels of discomfort, although this commonly lessened over time. For Halime, this discomfort related to a sense of intrusion, while for Gerard this was feeling he had done something wrong which made him the focus of attention.

They were intruding into my space... but towards the end of it though, I... accepted them. (Halime, client, FI)

So I was feeling a bit like a child, a naughty child or something...I was in the hot seat so to speak...but after a few sessions it seemed that...I was no longer in the hot seat because I would somehow move to an easier position... some of the pressure was taken off me. (Gerard, client, FI)

In a similar vein to Gerard, Conor and Melissa described feeling

uncomfortable, though for them this related to having to talk about their experiences. Melissa described talking about her addiction problems being especially difficult. For Conor, this was couched in terms of having to talk about painful past events, although his attitude to the sessions changed later. 
There were some issues I was uncomfortable about, but my case manager said we have to talk about them...It was hard to talk about the addiction, I felt ashamed, in front of mum and dad and siblings. (Melissa, client, BI)

At first it was difficult to talk about the different things happening, but then after we did it was good...I was just nervous and stressful (sic) when asked to talk about it, but then afterwards in hindsight when I look back I thought it was good. (Conor, client, FI)

Challenging but helpful. Families identified that even though some aspects of BFT were difficult, this was balanced by a view that it might be ultimately helpful and, to some extent, a necessary ingredient in the change process.

You are sitting there looking around at people, it felt a little bit like the heat was on...Oh I just think it's good to have discussion...I know it helps because the more you involve people the better it is. (Liz, mother, BI)

Yeah I reckon it has to be full on and actually get people out of their comfort zone to actually bring a change about. (Arthur, father, FI)

There were a few awkward moments, like role playing. [But] the role playing is the most important because you learn from it. (Ivan, client, BI)

Enjoyable aspects of the process. Clients described features of BFT that they found enjoyable. This ranged from being part of a family conversation to enjoying the humorous moments in sessions. Families frequently referred to humour 
and its importance seems to be in providing relief or contrast to the seriousness of the reason that families are meeting.

No I actually liked those conversations even on days when I haven't got that much to say or I find it difficult to put words together, I still always enjoy a conversation or... listening in...(Gerard, client, FI)

I was a bit more relaxed actually because I knew [my brother] would say something stupid, that was relaxing...but him being a bit stupid would make it even more shared around. (Conor, client, Fl)

It was good, it was funny because my sisters and the two therapists all got along and we found we were laughing and getting along and communication and it was interesting, it was pretty good. (Judith, client, BI)

\section{The Impact of BFT}

Families reported both positive and negative impacts from participating in BFT. The positive impacts were linked most often to the information sharing component of BFT and having more open discussions about their family member's illness and improved understanding of the mental illness. Families' disappointments were related to limitations in the delivery of anticipated benefits.

Talking more openly about mental illness. Families described how BFT had enabled them to talk more openly about mental illness. This could relate to specific symptoms such as suicidal thoughts or a more generalised idea of 'things being out in the open'. 
Sandra [case manager] came here and she said 'Halime, are you suicidal today?' 'No' and I'm thinking 'Jeez, I think she's [the case manager] putting things in her head' and she says 'No, no, no, that's not the case, you need to be up front with them'. And I thought 'she might be right. All right, I'll take over' ...We used to hide things, like we never used to say it openly...'(Umit, partner, Fl)

Well it sort of just got things off your mind...different things...got out in the open and everyone sort of discussed them more and then it was better. (Conor, client, FI)

Improved understanding of mental illness. Families commonly described how BFT had improved their understanding of mental illness. Two main processes were associated with this improved understanding. Firstly, the practitioner provided clients and family members with information about mental illness. This often led to changes for the client in managing their condition or for family members in how they responded to their relative's illness.

It was helpful, it was constructive. I learnt about the illness, and about the 'negative symptoms' and I had heard of them, but never had it explained, so now I understood about negative symptoms and the depression and the whole thing. (Adam, client, BI)

We did a lot of stuff...One of my first ones when I'm getting sick was 'what do I do? What triggers it?' We did that session, it was good. I'm more aware of 
the talking voices problems, it's helped. I get extra help now to deal with the voices, like going for a walk or listening to music. (Peter, client, BI)

Had I not had the sessions, I [would have] still thought yelling would help when in fact it makes it worse. (Jerry, brother, BI)

Secondly, clients shared their experience of mental illness with family members. This typically occurs in BFT as part of a practitioner-facilitated process that acknowledges the 'client as expert' in their illness. These sessions deepened family members' appreciation of their relative's illness and were emotionally powerful moments for families.

Melissa talked about her feelings, and her symptoms and her experiences, for her to open up to the family was a turning point and a high point.

(Amanda, mother, BI)

In one [of] the early sessions, the therapist asked me to explain my

symptoms, and I told my mum I thought she had been the devil, and she was amazed, and I realised it was just silly thoughts, just symptoms and I got the insight just by talking about it, (Melissa, client, BI)

We didn't realise she hears voices ALL THE TIME, it's sad to think this goes on all the time. (Kerrie, sister, BI)

The extent of change. Families' disappointments about the impacts of BFT related to limitations in the degree of change that occurred for the client, the extent 
to which improvements in family communication were not sustained and the failure of BFT to prevent relapse as described by Paula.

Where we are at now where Frank [client] has gone a little bit backwards.... I think with me... if l'm going to be doing something ... you want to know that yep...you wish it's $100 \%$ secure and it's going to fix it, .... I think my point is did we actually really touch the surface of the real problem (sic) to start with from the word go? (Paula, sister, Fl, whose consumer sibling relapsed after BFT sessions)

In my opinion Building Family Skills Together helps 60\%, the rest it doesn't change. It helps, but it does not cure, it does not fix the person. (Lidio, husband, BI)

I mean the objective of these sessions is to bring about change, and you have to have that momentum to actually bring about the change, and then settle the change, and make it part of you. The danger is that if you don't have that, you know people come along to the session and everything starts nicely, and you go away and it just disappears, and you don't actually get to the point of where the change becomes internalised and becomes part of you. (Arthur, father, Fl)

\section{The Role of the Practitioner}

Families frequently commented on the qualities and approach of the practitioners. This was noted at commencement and during participation in BFT. While clients and family members frequently described their experiences of 
practitioners in positive terms, they also identified circumstances in which they viewed the practitioner's approach as less helpful. While practitioner attributes and the quality of relationships were important in the experience of BFT, participating in BFT also had an impact on the ongoing relationship between practitioners and families.

Commencing BFT. The existing trust between the practitioner who was the case manager of the client and the family was important in the decision to commence BFT. Enthusiasm was also identified as an important attribute influencing the families' willingness to be involved.

Well we trust them as professionals... I thought it would be O.K. It is something that is probably going to be O.K. because Susan [case manager and BFT practitioner] said, she was not going to put us somewhere that was silly. (Liz, mother, FI)

She was just enthusiastic, she said that they had a service, we could go there or they would come to our house and try and help the family and me and I thought it was a good idea. (Halime, client, FI)

The approach of the practitioners. Family members often commented on the attributes of the practitioners. These related to their manner, genuine caring and their acknowledgement of the importance of family members.

It was the way they spoke to you, they spoke nicely (Ivan, client, BI) 
... in the previous experiences we'd just go through the process in and out you know, you don't want a problem you just get rid of it, whereas with all the people that we've dealt [with] in this service over here it's always been caring. (Arthur, father, FI)

The therapists really listened to you and were helping you, not just as an extra to the patient...I felt important and validated (Michelle, mother, BI)

While there was a general sense of appreciation and valuing of practitioners' work with families, family members did not always agree with the way in which BFT was conducted. Areas of concern spanned questioning the extent to which their relative was encouraged to talk in sessions, the focus being on family members rather than the client and the client's participation when they were unwell.

There is still a question in my mind about $R$ (client) not being drawn out enough - whether we should just not talk and let him, or whether [we] should have said something. (Irene, mother, BI)

It was hard to get across to the therapists that why are you working on us, not him. We were doing [a] session when he was unwell, so there was no point to the discussions because he was paranoid and there were things in his head. (Renee, mother, BI)

Strengthening relationships. Families commented on how participating in BFT had broadened the practitioner's relationship with the client to include the family. The quality of the relationship between family members and the practitioner was also improved. 
The entire family has [a] good relationship with case manager now. (Melissa, client, BI)

Oh yeah, you probably do get closer with the case manager. She does know you more intimately now...you see her a bit more so you feel more confident and that with her. (Angelo, brother, FI)

\section{Discussion}

The analysis of post-intervention interviews revealed that family experiences of BFT in this study were both similar to, and different from, the experiences of families reported in previous studies. Consistent with the previous studies, the attributes of the practitioners and the relationship between families and the practitioner featured prominently. This was evident from the point of initial engagement as found by James et al. (2006). It was also significant in families' positive experience of participating in BFT. BFT was also seen as improving the relationship between family and practitioner as found by Budd and Hughes (1997). Families' observations of the caring and interested manner of practitioners resonate with the earlier findings about genuineness as a particularly important attribute (Campbell, 2004).

More than in previous studies, the interviews highlighted that family members valued the information-sharing component of BFT. Information about the client's condition provided by practitioners was seen as useful in informing how both the client and their family members responded to the illness. The most profound experiences in understanding the impact of mental illness for families were when the client shared their personal experience of symptoms. This led to a richer 
appreciation by family members of the day-to-day reality experienced by the client and enhanced empathy. These sessions were also seen as beneficial because they involved a process of 'opening up' discussion in families about mental illness in circumstances where such conversations had been avoided. "Deep conversation" can be thought of as a task that was achieved through the with-in family alliance(Lambert et al., 2012; Priebe \& McCabe, 2006) (the shared sense of purpose within the family that is nurtured by the practitioner (Lambert et al., 2012)) as participants increased the regard and empathy for each other as sessions progressed.

The practitioner's attributes and their relationship with the family and the information sharing component of the model were important in how families perceived the benefits of family psychoeducation (Fife, Whiting, Bradford, \& Davis, 2014). In line with the conclusions of James et al. (2006), family members' trust in practitioners, or the therapeutic alliance, created the context for families to benefit from BFT. In a reciprocal way, when clients are supported to share their experience of mental illness, relationships are strengthened within the family and between the family and the practitioner. This suggests the acquisition of skills and knowledge, the development of therapeutic alliance and the development of with-in family alliance, family intimacy and capacity for deeper conversations developed hand in hand (Fife et al., 2014).

In contrast to the overwhelmingly positive previous accounts of BFT, families reported significant discomfort in sessions. Being involved in sessions was especially daunting for clients, particularly in the early stages when they felt they 
were the focus of attention and had to talk about their experiences. Family members also reported feeling uncomfortable, yet acknowledged that this discomfort might be necessary for meaningful change to occur. Interestingly then, the very experiences that made clients and family members feel uncomfortable, in particular talking about the illness directly, were also what they appreciated most about BFT. This has implications for how clients and their family members can be best supported so that initial discomfort does not lead to early withdrawal from BFT.

While these findings relate to those who have participated in BFT, they may also apply to those clients or family members who decline the intervention. For clients in particular, negative anticipation of what will happen in sessions may be an important factor in accounting for why families declined offers of BFT as described earlier. This is significant in an adult mental health context where practitioners often need to convince the family of the value of participating in BFT and where the families' involvement is contingent on the willingness of the person with the diagnosed condition to participate.

Families' disappointments about participating in BFT were more prominent in this study than in previous accounts. Families raised questions about whether there was sufficient time and attention paid to sustain new and beneficial skills. Family members themselves identified the importance of spending more time on these skills and of revisiting them in sessions. This may be the result of sessions led by practitioners new to BFT who may not have focussed sufficiently on ensuring families had acquired these skills. In addition, working with families from non-English speaking backgrounds involved time-consuming use of interpreters. This may have 
made it harder to provide the required additional sessions needed to consolidate learning.

Family members were especially disappointed when BFT did not meet their expectations regarding improvement in their relative's functioning or if a relapse occurred. This suggests the importance of achieving a balance between instilling hope through promoting the benefits of BFT and reminding families that it is not possible to guarantee positive outcomes. More broadly, an appreciation of families' differing experiences of BFT has implications for practice, training and research.

\section{Implications}

The value of 'non-specific' factors such as therapeutic alliance in manualised treatment approaches should be emphasised in the training of practitioners in BFT. There is a need to balance content and process, structure and flexibility, depth and lightness in the family sessions (Falloon, 2015). Practitioners need to assist families to have the "difficult" discussions that build intimacy, as much as build the skills which support these interactions.

In terms of engagement of families in BFT, there are a number of factors that may be helpful. As Flaskas (2016) notes it is important for practitioners to factor in the 'strangeness' of family therapy for families and to recognise how anxious and vulnerable family members can feel. The current study highlighted the particular vulnerability of the family member diagnosed with a mental illness. This suggests that practitioners can help their clients and family members manage their anxiety by anticipating, normalising and directly addressing feelings of discomfort. 
There have been encouraging results in relation to the use of motivational interviewing techniques to improve family engagement in family psychoeducation (Sherman et al., 2009). Carer and consumer advocates, especially those with prior training or experience of BFT, may play a role in supporting families in joining sessions. Training in Family Sensitive Practice might help develop trust between practitioners and families that would make it easier for families to take the difficult first steps to participate in interventions such as BFT (Furlong, 2001). There may also be a role for information sessions about BFT in which families who are considering BFT hear about 'navigating the initial difficulties' from families with lived experience.

Given the complexity of conducting family sessions, the training and supervision of practitioners may need to be enhanced to include skills in building the therapeutic alliance and in "containing" anxieties (Falloon, 2015). Practitioners may need access to a variety of other practitioners and their corresponding therapy styles - thus there is value in co-working with several other practitioners, peer mentoring and supervision groups to provide such exposure.

Outcome studies of BFT and other forms of family psychoeducation should routinely include measures of therapeutic alliance, knowledge, satisfaction and within-family alliance. Process variables such as therapeutic alliance might be considered more often in program evaluation studies, especially as proximal (immediate) outcome measures. The link between tasks such as "in-depth" conversations, family and therapeutic alliances and outcomes is a particularly important area for further empirical investigations (Smerud \& Rosenfarb, 2008). 


\section{Conclusion}

Although BFT is a manualised treatment, our findings suggest greater

emphasis on the value of 'non-specific' factors such as engagement and therapeutic

alliance would be beneficial in the implementation, training, practice and

assessment of BFT programs. In this way the current problems associated with

initial engagement and retention of families in BFT may be addressed so that more

families can experience the benefits of this and other effective family interventions.

\section{References}

Berglund, N., Vahlne, J. O., \& Edman, A. (2003). Family intervention in schizophrenia-impact on family burden and attitude. Social Psychiatry and Psychiatric Epidemiology, 38(3), 116-121.

Budd, R., \& Hughes, I. (1997). What do relatives of people with schizophrenia find helpful about family intervention? Schizophrenia Bulletin, 23(2), 341-347.

Campbell, A. S. (2004). How was it for you? Families' experiences of receiving behavioural family therapy. Journal of Psychiatric and Mental Health Nursing, 11(3), 261-267.

Fadden, G. (2006). Training and disseminating family interventions for schizophrenia: developing family intervention skills with multi-disciplinary groups. Journal of Family Therapy, 28(1), 2338.

Falloon, I. (2015). Handbook of behavioural family therapy. Hove: Routledge.

Falloon, I., Fadden, G., Mueser, K. T., Gingerich, S., Rappaport, S., McGill, C., . . Gair, F. (2004). Family work manual (pp. 116). Birmingham United Kingdom: Meriden, The West Midlands Family Programme.

Fife, S. T., Whiting, J. B., Bradford, K., \& Davis, S. (2014). The Therapeutic Pyramid: A Common Factors Synthesis of Techniques, Alliance, and Way of Being. Journal of Marital and Family Therapy, 40(1), 20-33.

Flaskas, C. (2016). Relating therapeutically in family therapy: pragmatics and intangibles. Journal of Family Therapy, 38(1), 149-167.

Furlong, M. (2001). Constraints on family-sensitive mental health practices. Journal of Family Studies, 7(2), 217-231.

Glynn, S. M., Randolph, E. T., Eth, S., Paz, G. G., Leong, G. B., Shaner, A. L., \& Vort, W. V. (1992). Schizophrenic symptoms, work adjustment, and behavioral family therapy. Rehabilitation Psychology, 37(4), 323.

Haddock, G., Eisner, E., Boone, C., Davies, G., Coogan, C., \& Barrowclough, C. (2014). An investigation of the implementation of NICE-recommended CBT interventions for people with schizophrenia. Journal of Mental Health, 23(4), 162-165.

Harvey, C., \& O'Hanlon, B. (2013). Family psycho-education for people with schizophrenia and other psychotic disorders and their families. The Australian and New Zealand Journal of Psychiatry, 47(6), 516-520.

Hayes, L. (2014). Hope and recovery in a family treatment for schizophrenia: A program evaluation of a Family Psychoeducational Intervention. (Doctoral Thesis), University of Melbourne, Melbourne. 
James, C., Cushway, D., \& Fadden, G. (2006). What works in engagement of families in behavioural family therapy? A positive model from the therapist perspective. Journal of Mental Health, 15(3), 355-368.

Lambert, J. E., Skinner, A. H., \& Friedlander, M. L. (2012). Problematic Within-Family Alliances in Conjoint Family Therapy: A Close Look at Five Cases. Journal of Marital and Family Therapy, 38(2), 417-428.

Magliano, L., Fiorillo, A., Fadden, G., Gair, F., Economou, M., Kallert, T., . . Maj, M. (2005). Effectiveness of a psychoeducational intervention for families of patients with schizophrenia: Preliminary results of a study funded by the european commission. World Psychiatry, 4(1), 45-49.

Magliano, L., Fiorillo, A., Malangone, C., De Rosa, C., \& Maj, M. (2006a). Implementing psychoeducational interventions in Italy for patients with schizophrenia and their families. Psychiatric Services, 57(2), 266-269.

Magliano, L., Fiorillo, A., Malangone, C., De Rosa, C., \& Maj, M. (2006b). Patient functioning and family burden in a controlled, real-world trial of family psychoeducation for schizophrenia. Psychiatric Services, 57(12), 1784-1791.

Mairs, H., \& Bradshaw, T. (2005). Implementing family intervention following training: What can the matter be? Journal of Psychiatric and Mental Health Nursing, 12(4), 488-494.

McFarlane, W. R. (2016). Family Interventions for Schizophrenia and the Psychoses: A Review. Family Process, n/a-n/a. doi:10.1111/famp.12235. Retrieved from http://dx.doi.org/10.1111/famp.12235

Montero, I., Asencio, A., Hernández, I., Masanet, M. J., Lacruz, M., Bellver, F., . . Ruiz, I. (2001). Two strategies for family intervention in schizophrenia: a randomized trial in a Mediterranean environment. Schizophrenia Bulletin, 27(4), 661.

Mueser, K. T., \& Glynn, S. (1999). Behavioral family therapy for psychiatric disorders (Second ed.). Oakland, California: New Harbinger Publications.

Mueser, K. T., Sengupta, A., Schooler, N. R., Bellack, A. S., Xie, H., Glick, I. D., \& Keith, S. J. (2001). Family treatment and medication dosage reduction in schizophrenia: Effects on patient social functioning, family attitudes, and burden. Journal of Consulting and Clinical Psychology, 69(1), 3.

O'Hanlon, B. (2015). Building Family Skills Together: implementing a family intervention in an adult mental health team. (Doctor of Philosophy), La Trobe University, Melbourne.

Onwumere, J., Grice, S., \& Kuipers, E. (2016). Delivering Cognitive-Behavioural Family Interventions for Schizophrenia. Australian Psychologist, 51(1), 52-61.

Patton, M. Q. (2002). Qualitative research and evaluation methods (3rd Edition ed.). Thousand Oaks: Sage Publications Inc.

Pharoah, F., Mari, J., Rathbone, J., \& Wong, W. (2010). Family intervention for schizophrenia. Cochrane Database of Systematic Reviews, 12.

Priebe, S., \& McCabe, R. (2006). The therapeutic relationship in psychiatric settings. Acta Psychiatrica Scandinavica, 113, 69-72.

Randolph, E. T., Eth, S., Glynn, S. M., Paz, G. G., Leong, G., Shaner, A., . . Liberman, R. (1994). Behavioural family management in schizophrenia. Outcome of a clinic-based intervention. The British Journal of Psychiatry, 164(4), 501-506.

Rummel-Kluge, C., Pitschel-Walz, G., Bauml, J., \& Kissling, W. (2006). Psychoeducation in schizophrenia--results of a survey of all psychiatric institutions in Germany, Austria, and Switzerland. Schizophrenia Bulletin, 32(4), 765-775.

Saldaña, J. (2009). The coding manual for qualitative researchers. London: Sage Publications Ltd.

Schooler, N. R., Keith, S. J., Severe, J. B., Matthews, S. M., Bellack, A. S., Glick, I. D., . . Frances, A. (1997). Relapse and rehospitalization during maintenance treatment of schizophrenia: the effects of dose reduction and family treatment. Archives of General Psychiatry, 54(5), 453463.

Sherman, M. D., Fischer, E., Bowling, U. B., Dixon, L. B., Ridener, L., \& Harrison, D. (2009). A new engagement strategy in a VA-based family psychoeducation program. Psychiatric Services, $60(2), 254-257$. 
Smerud, P. E., \& Rosenfarb, I. S. (2008). The therapeutic alliance and family psychoeducation in the treatment of schizophrenia: An exploratory prospective change process study. Journal of Consulting and Clinical Psychology, 76, 505-551.
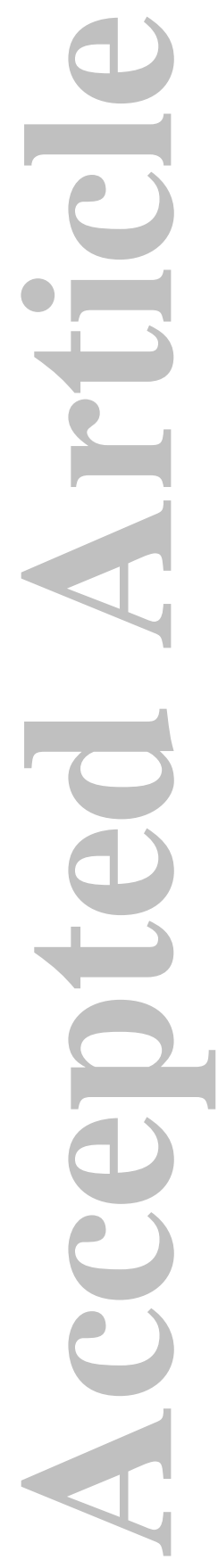


\section{University Library}

\section{- M M I N E R VA A gateway to Melbourne's research publications}

Minerva Access is the Institutional Repository of The University of Melbourne

Author/s:

O'Hanlon, B;Hayes, L;Perlesz, A;Harvey, C

Title:

Understanding the complex family experiences of Behavioural Family Therapy

Date:

2018-02-01

Citation:

O'Hanlon, B., Hayes, L., Perlesz, A. \& Harvey, C. (2018). Understanding the complex family experiences of Behavioural Family Therapy. JOURNAL OF FAMILY THERAPY, 40 (1), pp.45-62. https://doi.org/10.1111/1467-6427.12139.

Persistent Link:

http://hdl.handle.net/11343/291893 